\title{
Sensitivity of the Investments of Sub-Saharan Firms to Financial Constraints
}

\author{
Elie Ngongang \\ Department of Quantitative Techniques, Faculty of Economic and Management, University of Yaounde II, Yaounde, Cameroon \\ Email: ngongother@yahoo.fr
}

Received January 7, 2013; revised February 11, 2013; accepted February 22, 2013

\begin{abstract}
Investment is an important instrument of growth and competitiveness for non financial firms. However, these firms have limited financial resources (or liquidity) at their disposal. The financial constraint is defined as a conditionality to be met in order to have access to liquidity by assuming that the information held by shareholders is perfect, and that financial markets are efficient. We have attempted in this study to analyze empirically the impact of these financial constraint on the investments of Sub-Saharan manufacturing firms. We carried out an empirical analysis of a sample of 73 firms belonging to the different manufacturing sectors listed on the stock market during the period 1998-2009, and by taking inspiration from panel data methodology. The empirical tests emphasize the fact that the manufacturing firms of Sub-Saharan countries, including the smallest ones and those with which financial institutions have no close relations, witness an environment with a strong information asymmetry between borrowers and lenders. These firms are constrained in their access to external indebtedness due to the levelling-off of indebtedness. However, taking account of uncertainty could enrich the extension of this study.
\end{abstract}

Keywords: Investment; Financial Constraints; Indebtedness; Information Asymmetry; Financial Flows; Sub-Saharan Africa

\section{Introduction}

Investment is the operation which consists for a firm in increasing its capital stock (machines, equipments of all types, goods of all kinds, etc.) with the prospect of future growth and competitiveness. On the accounting level, it represents an expenditure on a movable, corporeal or incorporeal property acquired or created by the firm, and intended to remain durably in the same form in the firm. On the theoretical level the analyses carried out on the firms' sources of growth, investment takes up a predominant place. Its high volatility contributes to the fluctuations of the firm in a non-negligible way. Its role in the short term and its role in the long term make of investment a key variable for the firm. Understanding the evolution of investment behaviour requires an identification of the main variables which guide this behaviour.

Glesne and Legris [1] assume that investment is the result of the combination: 1) of an opportunity to invest, which may be the occasion of pressure on the firm's demand, added to a shortfall in the production capacity; 2) of the will to invest, which is the direct corollary of the ability of the investment project to satisfy certain requirements of the managers; and 3) of the capacity to invest, which is linked to the possession by the manager of the financial means necessary for the implementation of projects which satisfy the above characteristics. Thus, investment is a particularly decisive variable for nonfinancial firms. Its degree of aversion to risk is to be taken into account, just as the financing constraint when the firm is set in an environment where it has access to a financial market.

The financial constraint is defined as a conditionality to be met in order to have access to liquidity, by considering the fact that stockholders information is perfect and that financial markets are efficient. The asymmetry of information between stockholders, the banks and executives can modify the structure of financing. It refers to the nature of incentives to the efficiency of the firm's executives.

Investment therefore appears to come under the multiple and complex objectives which must also take account of the influence of long-term programmes that aim at increasing the firms' effectiveness and competitiveness. The investment of manufacturing firms has recently and very often taken the form of external growth, that is, the repurchase of existing firms rather than a physical investment. Generally speaking, these firms increasingly hold securities.

The different financial and econometric approaches to investment collide against the problems of taking account 
of the financial constraints that keep firms from investing as much as they would wish. Under the assumption of one financial market, Modigliani and Miller [2] demonstrated the absence of interactions between investment and financing.

But during the last twenty five years, the separation between the real sphere and the financial sphere tends to become less pronounced. This situation is due to the development of an abundant theoretical and empirical literature which deals with the impact of financial constraints on the structure of the firm as far as investment is concerned. The study by Fazzari, et al. [3] constitutes the point of departure of this empirical literature which is explicitly based on theoretical contributions that deal with the asymmetry of information and its impact on the existence of financial constraints. According to these authors, the firms most likely to be constrained in their external financing are small-sized and young.

Generally speaking, investment is a significant instrument for the growth and competitiveness of non-financial firms. However, they have limited financial resources (liquidities) at their disposal. This problem is recurrent in the non-financial firms of North-American countries (and it increasingly occurs in Sub-Saharan countries) and in the presence of financial constraints due to information asymmetries. The assumption used to detect a financing constraint is that of Fazzari, et al. [3]. They distinguished constrained from unconstrained firms through one of the fundamental characteristics of the firm: the availability of internal funds in direct relation with its financial status. But most of the studies do not confirm the results arrived at by these authors. The use of the sensitivity of investment to operating cash flows have generated heterogeneous results, and the most recent studies carried out by Carpenter and Guariglia [4], Gugler, et al. [5] have not found definitive answers.

Minton and Schrand [6] used the volatility of internal funds to analyze the impact of the debt or of equity capital on investment. Consequently, the very identification of appropriate criteria to measure the firms' sensitivity to financial ratios gives rise to problems.

One major question emerges from all this development: What is the influence of financial constraints on the investment decisions of Sub-Saharan manufacturing firms? In other words, do financial constraints have an impact on the investments of manufacturing firms in the SubSaharan context?

We may envisage several methods for answering these questions. A possible method may consist of specifying a reduced-form model such as Vogt [7], Kaplan and Zingales [8], Heitor and Campello [9] who specify the empirical relationship between Cash-flows, debts, fixed investment capital, and equipment expenditures. Though it is quite interesting, this method become more complex at the level of data, and when there exist variables in first differences in the estimated model, as well as exogenous variables which are lagged one period.

It is for this reason that one may specify an Euler equation (version Whited [10], Bond and Meghir [11]), which is revisited in their recent studies by Daoudand Kammoun [12], with the firm's profit maximization program under different constraints. It has the advantage of taking the recurrent nature of the decisions of firms, information that is necessary to determine the optimal trajectory of investment, to measure the sensitivity of the firms' investment to financial constraints considering the information available at each period. This study fits into this perspective.

The objective of this study is therefore to analyze empirically the impact of this financial constraint on the investment decisions of Sub-Saharan manufacturing entreprises. In other words, our aim is to explain the influence of financial constraints on the investments of manufacturing entreprises in the context of Sub-Saharan countries. To test the hypothesis of the presence of a relationship between financial constraints and investment, it is useful to examine in Section 2 below, the theoretical motivations, then in Section 3 the methodological approach, and lastly in Section 4, the results of the study and their interpretation.

\section{Review of the Literature}

In the exercise of their daily activities, firms are confronted by certain situations which may paralyze their operation. This is essentially summarized in the problems they face in financing the activities of the firm.

Actually, there exists a multiplicity of choices for a firm when it faces financial problems. But the firm may be incapable of using these alternatives to solve these problems owing, for instance, to the indebtedness clause to be respected. Thus, the firm is limited in its decision making, linked to financial constraints.

In general, under the assumption of a limited control of the managers, the stockholders prefer a distribution of part of the internal gross cash flow to a total re-investment of this liquidity in the projects. However, if external financing becomes imperative when self-financing is insufficient to finance profitable projects, firms have recourse to indebtedness and sometimes to the issuing of new stocks.

\subsection{Sensitivity of Investment to Cash Flows: A Measure of the Degree of Financial Constraints}

The literature on financial constraints has been an area of research interest for several authors, and each of them has chosen a firm's characteristic which seems to explain 
this situation better.Fazzari, et al. [3] used the dividends distribution criterion to characterize the firms which are financially constrained.

Fazzari, et al. [3] have integrated the cash-flow variable among the factors that explain investment. They have analyzed the sensitivity between the cash flow and investment with a view to confirming or invalidating the assumption of the existence of a financial constraint in the presence of market imperfections. These authors used the distribution of dividends as a constraint because it has an informative content. According to this criterion, the firms which distribute more dividends are the most financially constrained, all the more since the managers thus have a reduced internal financing capacity.

These studies open a new debate on the question of the validity of using the sensitivity of investment to cash flows as a measure of the degree of the firms' constraints. This debate takes shape when Kaplan and Zingales $([8,13])$ wonder about the effectiveness of using the sensitivity of investment to cash flows to explain the firms' financial constraints. They suggest, for firms that disburse small amounts of dividends, that the sensitivity differences which appear are partially attributable to differences in the firms' rates of growth. Thus, the sensitivity of investment to cash flows may be due to the preferences of managers who prefer financing their investments with internal liquidity (cash flow).

It emerges from previous works that the firms' investment policy is sensitive to the fluctuations of cash flows. In addition, the most financially-constrained firms have higher investment sensitivity to cash flows than those facing weaker financing constraints. Other authors use the indebtedness level to explain the firms' financial constraints.

\subsection{Sensitivity of Investment to the Debt: A Risk Linked to the Financial Structure}

According to the theory developed byModigliani and Miller [2], the market value of a firm does not depend on its capital structure. External and internal financings are substitutable and the investment decisions of a firm are totally independent of its financing decisions and of financial factors such as liquidity, the indebtedness level or dividends policies. However, some frictions linked to information asymmetry problems, may lead to dependence between the investment and financing decisions. For this reason, in the presence of imperfections on the credit market, a central role is given to financial indebtedness conditions.

In the context of financial theory, Modigliani and Miller [2] show that in the presence of a perfect financial market, the financial structure appears to be neutral on the market value of the firm. These authors suggest a maximal indebtedness to make the most of the advan- tages brought about by the fiscal economy, and this, when the financial problem is without a distress cost.

According to Modigliani and Miller [2], the firm is indifferent in terms of financing its investment through indebtedness, retention of profits or through the issuance of stocks. This situation leads to some form of equality between the yield required by stockholders and the interest rate of creditors. The initial model of Modiglianiand Miller [2] has been criticized by several researchers, notably the simultaneous introduction of taxation and failure costs. In addition, the deduction of financing costs from profit may reduce the firm's self-financing, and thus facilitate a continuous increase in indebtedness. Furthermore, the increase in indebtedness entails an increased risk of failure: for example, the optimal level of indebtedness is obtained by arbitrage between the fiscal advantage linked to the debt and the cost of the risk of failure.

Several studies, particularly those of Nivoix, et al. [14], as well as Daoud and Kammoun [12], show that financeing by issuing new stocks represents a small share of external financing, the effect of financial constraints which are thus associated with it would be significant on the decisions of the firm.

\subsection{Sensitivity of Investment to Tobin's q: A Transmission of Financial Shocks (Role of Financial Variables)}

According to Tobin [15], firms invest in new projects if the market value of the firm is higher than its accounting value. In other words, if the market increases the value of these beyond what they did cost (or if the market value them beyond what they cost). According to this author, this ratio is the only relevant indicator which can explain the firms' investment decisions. This ratio therefore serves as an incentive indicator to investment. Theoretically, this is due to the uncertainty that weighs on the (market) outlets, and the irreversibility of investment decisions that there exists a relationship between investment and profitability. Thus, the higher Tobin's q is, the more the firms invest and take the risk of overcapacity when facing an uncertain demand (Malinvaud, [16,17]).

Empirical studies on this argument were many and they gave some support to the relationship between investment and Tobin's q. They traditionally use the average $\mathrm{q}$ of Tobin which is evaluated with financial market data instead of marginal q. The average q may be measured directly from the value of the firm on the market. The marginal q is the only relevant ratio in theory, which provides the signal in the investment decision of the firm's manager. In effect, one does not observe the marginal q which is the implicit value of a new unit of capital installed relative to the cost of this unit, or which is the same thing at the optimum of the firm's programme, 
the present value of profit flows which will be reported in the future by a dollar of new investment. The marginal q only coincides with the average q under certain conditions: a financial environment which verifies the theorem of Modigliani and Miller [18], a production function with constant returns to scale, and a homogenous function of costs adjustments of degree one, and the firm is a pricetaker (Hayashi, [19]).

Vogt [20] shows through an empirical model the effect of flows of cash flows on the value of Tobin's q under the assumption of high agency costs. The model is then enlarged to appreciate how the dividends (a means of reducing the flow of cash flow and of controlling the managers) affect Tobin's q. Jensen [21] defines the flow of cash flow as the "excess gross margin of self-financing" required to finance all the projects which have the net positive present value discounted at the appropriate cost of capital" In this regard, when the flow of cash flows is present and the control of the stockholder is incomplete, the agency problem of the type of policymaker suddenly appears.

Indeed, the manager tends to over invest (to invest in projects with a negative net present value (NPV) to capture the pecuniary and non-pecuniary advantages (allocations) of the firm's growth Jensen and Meckling [22], whereas the stockholders would prefer the distribution of dividends in order to reduce the flows of cash flows (Langa and Litzenberger, [23]), and hence to control the manager. There exist complicated models which help to test Tobin [15] assumptions. However, they provide little additional insight or perspicacity. Vogt [20] then proposes to use a simple estimation method to test the influence of Tobin's average q on the firms' investments.

Vogt [20] then wonders about whether the importance of cash flows in the investment decisions of firms consists of a waste of cash flows or whether the firms really face up to costly external financings due to the asymmetry of information phenomenon. Two aspects of this situation are then developed: the theoretical implications of cash flows and of Tobin's q.

The study by Vogt [20] shows that investment expenditures financed by cash flows are marginally unproductive for the firms and at the same time, identify the potential sources of their ineffectiveness. Encashed cash flows finance the growth of large firms, whereas firms with small dividends tend to destroy their values. The importance of dividends as a method for attenuating cash-flows agency costs is increasingly confirmed. The policymakers of the firms that are rich in terms liquidity flows, may consider increasing disbursements of dividends as a method for increasing the effectiveness of their investment expenditure decisions. However, a continuous policy of "high dividends disbursement" may also be a signal for shareholders that an additional (costly) control is useless.

The main assumption in the theoretical work on the firm's financial constraints is that these constraints entirely manifest themselves in the costs of external financing which are generally very high. This assumption poses two types of research problems (Heitor and Campello [24]). Firstly, it reduces the comprehension of financial constraints. However, the firms often practically face credit rationing. To explain the phenomenon of credit rationing for example, Jaffee and Modigliani [25] mentioned the effect of uncertainty and of the risk of failure of the firm which give rise to an information cost on the supply of credit. These authors add that the lender undertakes credit rationing in the case where the demand for credit exceeds the supply, for a given interest rate. Secondly, they give rise to the debate on the real implication of financial constraints in the firms' investment decisions. Heitor and Campello [24] develop a theory which explains the relationship between the firm's investment and cash flow when the firms face credit volume constraints. They show that when the firm's investments and the use of external financing are endogenously linked, an increase in the sensitivity of investments to cash flow is expected. In an empirical perspective, their analyses suggest a coherent way of identifying the impact of financial constraints on the investment of the firm. However, their results are manifestly different from theoretical predictions.

In a second approach, Heitor and Campello [9] use the link between financial constraints and the firm's demand for liquidity to develop a new test of the effect of financial constraints on the financing policy of the firm. The effect of financial constraints may be captured by the propensity of a firm to economize on the progressive cash flows of liquid money ("the sensitivity of the cash flow of money"). For this reason, while constrained firms should have a positive sensitivity to economize on liquid cash flow, those that are unconstrained should not be systematically linked to cash flows. They evaluate the cash flow of liquid money by using a large sample of industrial firms during the period 1971-2000. They note that the firms that are more likely to be financially constrained present liquid money cash flow sensitivity significantly positive and different from zero, whereas the firms that are not constrained are not. Also compatible (in agreement) with their argument, they note that the liquid cash flow sensitivity of constrained firms increases during recessions, while that of unconstrained firms remain unchanged thanks to innovations.

\subsection{Theoretical Formalization Linking Financial Constraints and Investment}

The role of financial variables in the explanation of the firms' investment takes up an important place in the fi- 
nancial theory of the firm. It depends on the value of the firm, hence the use of financial ratios as explanatory variables in order to test the effect of financial constraints on investment.

The approach through Euler's investment equation, integrated by Abel $[26,27]$, empirically tested afterwards by Whited [10], and Bond and Meghir [11], though deriving from the firm's profit maximization program under different constraints, takes into account the recurrent nature of the firms' decisions, but reduces the conditions of information only to those that are important to determine the optimal trajectory of investment, given the information available in each period.

Whited [10], and Bond and Meghir [11] use Euler's equation to test the first order conditions of the firm's profit maximization program. This technique does not require the measurement of Tobin's q. Their approach implies the imposition of an exogenous constraint on external financing, and tests the influence of this constraint on the firms' investment. It emerges from their result that dividends may indeed serve as a signalling mechanism. Their payments are used to separate the firms that have favourable internal information from those that do not. In addition, the firms that exhaust their reserves and hence lack the capacity to distribute dividends are generally obliged to depend on external financing.

According to Azofra and Lopez [28], the use of Euler's equation without financing constraints on panel data has presented a net divergence depending on whether the estimation takes account of the totality of the sample or only the sub-samples of firms which are the most subjected to information problems, whereas the works of Whited [10], and Bond and Meghir [11] present a bad specification. In the work of Azofra and Lopez [28], the result is quite the opposite since the equation must not be rejected as a function describing the investment process of the firms least subjected to the asymmetry of information.

Under the assumption of the existence of imperfect financial markets, this model thus shows the influence of the financial situation of firms on the conditions of access to external financing (cost and availability). Therefore, the expression of our equation will be simply established. It will take into account the impact of financial ratios on the investment decision such as the effect of the debt, Tobin's q, and the cash flows of the firm.

\section{The Methodological Approach}

We take inspiration in our empirical approach from the model similar to those of Bond and Meghir [11], Jaramillo et al. [29], Azofra and Lopez [28], Rosenwald [30], which is revisited by Daoud and Kammoun [12] and which permit to establish an Euler equation of capital accumulation. This approach permits us to build our investment equation, which here is considered as the result of the first order condition of the optimization of the value of the firm under financial constraints. Thus, in this model, the maximization of the value of the firm may be given as follows:

$$
\operatorname{MAX}\left(V_{t}\right)=E_{t} \sum_{i=0}^{\infty} B_{t}^{i}\left[\gamma_{t+1} D_{t+i}-S_{t+1}^{n}\right]
$$

For this reason, $\operatorname{Max}\left(V_{t}\right)$ is therefore equal to the expectation $\left(E_{t}\right)$ of the present value of the sum $\left(B_{t}\right)$ of present and future returns $\left(D_{t}\right)$ which take account of taxation $\left(\gamma_{t}\right)$ and the dilution property rights due to the issue of new stocks $\left(S_{t}\right)$. This maximization of the value of firm is subject to the following which must be respected:

The constraint linked to the dividends of the firm, which is given by:

$$
\begin{aligned}
D_{t}= & \left(1-\tau_{t}\right)\left[P_{t,} F_{t}\left(K_{t}, L_{t}\right)-G\left(K_{t}, I_{t}\right)-w_{t} L_{t}\right. \\
& \left.-i_{t} B_{t-1}-A\left(B_{t-1}, P_{t-1}^{K}, K_{t-1}\right)\right] \\
& -P_{t} I_{t}+\left(B_{t}-B_{t-1}\right)+S_{t}+C_{t}
\end{aligned}
$$

where $\left(L_{t}\right)$ and $\left(K_{t}\right)$ are respectively the labour rand capital variables at time $t, A\left(B_{t-1}, P_{t-1}, K_{t-1}\right)=$ informamation asymmetry costs represented here by the agency function, which means, a function of the level of the debt and of capital. $\left(S_{t}\right)=$ new stocks issue; $\left(D_{t}\right)=$ dividends; $\left(C_{t}\right)=$ endowments to amortizations; $\left(w_{t} L_{t}\right)=$ share of labour; $\left(i_{t} B_{-1 t}\right)=$ reimbursement of interests; $F\left(K_{t}, L_{t}\right)=$ function de production which depends on the variables labour $\left(L_{t}\right)$ and capital $\left(K_{t}\right) ; G\left(K_{t}, I_{t}\right)=$ adjustment cost function, assumed to be convex to investment; $P_{t}=$ the level of output prices; $P_{t-1}^{K}=$ price of capital, and $\tau_{t}$ the rate of the tax on companies.

The classical constraint of capital accumulation $K$

$$
K_{t}=I_{t}+(1-\delta) K_{t-1}
$$

The constraints linked to the issue of stocks, dividends, and debts must be positive:

$$
D_{t} \geq 0, S_{t} \geq 0 \text { et } B_{t} \geq 0
$$

And finally, the constraint linked to setting a ceiling on the level of indebtedness:

$$
N E_{t} \geq\left[\frac{B_{t}}{P_{t}^{K} K_{t}}\right]
$$

The special feature of this model is the presence a new additional constraint in the maximization program which here imposes a ceiling on the firm's level of indebtedness, as well as an agency cost function in the definition of the dividend. This is a special feature of the model that distinguishes the classical approach which does not take the 
financing constraints into consideration.

For this reason, this agency function depends on two arguments, namely the level of the debts $(B)$, and the capital stock $(K)$. Similarly, we make the assumption that the higher $(B)$ is, the more incentive problems are severe $\left(A_{B} \geq 0\right)$ while the capital stock $(K)$ reflects the guarantee level which the firm gives to its financial institution, in order to promote greater trust and lower agency costs $\left(A_{K} \leq 0\right)$. The specification of functions helps us to obtain the following testable functional form:

Cost function linked to adjustment:

$$
G\left(K_{t}, I_{t}\right)=\left(\frac{c}{2}\right) \cdot\left(\frac{I^{2}}{K_{t-1}}\right)
$$

where, $c$ is a parameter representing the significance of adjustment costs, and $c \geq 0$.

Function linked to agency costs :

$$
A\left(B_{t-1}, P_{t-1}, K_{t-1}\right)=\left(\frac{r}{2}\right)\left(\frac{B_{t-1}^{2}}{P_{t-1}^{K} K_{t-1}}\right)
$$

where $\mathrm{r}$ is the average rate of investment, and $r \geq 0$.

Generally speaking, the firm does issue new stocks and does not pay dividends simultaneously. It does not finance its debt and does not issue stocks, and the dividend is strictly positive.

With these assumptions, the maximization of Equation (1) subject to constraints of Equations (2) and (5) permits to specify Euler's equation which is given in the following form:

$$
\begin{aligned}
&\left(\frac{I}{K}\right)_{i}= a_{1}\left(\frac{I}{K}\right)_{i t-1}+a_{2}\left(\frac{I}{K}\right)_{i t-1}^{2}+a_{3}\left(\frac{\Pi}{K}\right)_{i t-1} \\
&+a_{4}\left(\frac{Y}{K}\right)_{i t-1}+a_{5}\left(\frac{B}{K}\right)_{i t-1}^{2}+a_{6}\left(\frac{B}{K}\right)_{i t-1}+u_{i t} \\
& i=1, \cdots, N, t=1, \cdots, T
\end{aligned}
$$

where, the estimated values of the coefficients $\left(a_{5}\right)$ and $\left(a_{6}\right)$ which respectively capture the presence (or not) of a premium of access to external financing and a level of the debt ceiling.

If $\left(a_{6}=0\right)$ and $\left(a_{5} \prec 0\right)$, then the debt ceiling constraint is absent. The observed ratio of the debt to the capital stock representing the debt ceiling (see constraint (5) of the maximization of the firm's value) does not exist. For this reason, imperfections on the credit market are linked to agency problems. This situation constrains the firm in its access to external indebtedness, which is explained by the premium to be paid in addition to the interest rate set by the financial institution.

On the other hand, if $\left(a_{6} \prec 0\right)$ and $\left(a_{5} \succ 0\right)$, then the firm is subject to an indebtedness ceiling constraint, and an increase in the ratio of the debt to the capital stock reduces the advantage of financing through the debt, owing to the premium to be paid in addition to the interest rate without risk ( see constraint (2)).

\subsection{Econometric Specification}

The disturbance term $\left(\varepsilon_{i t}\right)$ of the investment equation, which is considered as being random, contains a variety of specification errors:

The differences between firms (particularly, in the areas of technology, the rate of depreciation, measures used etc.) affects the specification of the model to be estimated. These effects are captured by the presence of individual $a_{i}$ and temporal $a_{t}$, as well as by the term of idiosyncratic errors (the common $\varepsilon_{i t}$ ), $u_{i t}=a_{t}+a_{i}+\varepsilon_{i t}$.

The model to be estimated here is characterized by the presence of lagged endogenous variables among the explanatory variables of the model. This is an autoregressive model with a causality of the bias that must be considered: the correlation between explanatory variables, and individual specific effects. The origin of the bias is due to the fact that the rate of investment, $\left(\frac{I}{K}\right)_{i t}$ is a function of $a_{i}$, and hence $\left(\frac{I}{K}\right)_{i t-1}$ is correlated with individual specific coefficients.

Moreover, the effects may be correlated with other explanatory variables, in particular, the profitability term.

This technique boils down to highlighting, according Arellano and Bond [31], the generalized moments method (GMM) which makes the model appear in first differences. The equation to be estimated is given by:

$$
\Delta Y=a \Delta Y_{t-1}+b \Delta X+\Delta u
$$

where, $\Delta$ is the first difference operator such that $\left(\Delta X=X_{i t}-X_{i t-1}\right), \quad Y=$ variable $\left(\frac{I}{K}\right)_{i t}, X=$ matrix of explanatory variables, except for the lagged endogenous variable, and $b=$ the vector of corresponding parameters.

The data we use in this study show a great variability in individual decisions. They help to capture better the behaviour of investment in its detailed and structural aspects. These data take into consideration the accounting and financial data listed, and extracted from the stock markets of Nigeria, Ghana, and Libreville Gabon).

Note that our sample is composed of a panel of 73 manufacturing firms of different countries (more particularly the synthesis of the firms of Nigeria, Côte d'Ivoire, Ghana, Gabon, etc.), and different activity sectors such as (metallurgy, food processing, chemical, electricity, etc.) over the period 1999-2009.

Our approach carries out an estimation of the Euler investment equation over a ten-year period (1999-2009). In the model, we take account of the existence of vari- 
ables in first differences, as well as exogenous variables lagged one period. Thus, we are forced to eliminate the first two years (1999 and 2000) of the study period used. In order to decide in favour of the use of the model with a fixed individual effect or with a random effect, we carried out the Hausman [32] test.

The Hausman test is specified in the following manner:

The null hypothesis of the absence of correlation between the characteristics of manufacturing firms and explanatory variables is rejected, if the theoretical $\chi^{2}$ with $k$ (number of exogenous variables) degrees of freedom is lower than the determined $\chi^{2}$.

If the theoretical $\chi^{2}$ with $k$ degrees of freedom is higher than the calculated $\chi^{2}$, then the null hypothesis $H o$ is accepted and the specific effects are considered as being random; and furthermore, there are no specification errors.

Generally speaking, our model tests two constraints which may affect the investment decisions of a firm, namely: the setting of a ceiling and the increase in the cost of the debt as a function of the ratio of the debt to the capital stock.

This model may then be written as follows:

$$
\begin{aligned}
\Delta\left(\frac{I}{K}\right)_{i}= & a_{1} \Delta\left(\frac{I}{K}\right)_{i t-1}+a_{2} \Delta\left(\frac{I}{K}\right)_{i t-1}^{2}+a_{3} \Delta\left(\frac{\prod}{K}\right)_{i t-1} \\
& +a_{4} \Delta\left(\frac{Y}{K}\right)_{i t-1}+a_{5} \Delta\left(\frac{B}{K}\right)_{i t-1}^{2}+a_{6} \Delta\left(\frac{B}{K}\right)_{i t-1}+u_{i t}
\end{aligned}
$$

where,

$I=$ investment in equipment or $I_{t}=I M B_{t}-I M B_{t-1}$ (or the investment process of the firm $=$ investment expenditure);

$K=$ Stock $K$ or $K_{t}=(1-\delta) K_{t-1} ; \delta=$ a measure of the stock $K ; \Pi=$ gross operating result of the firm at time $t ; B=$ medium and long-term debt;

$Y=$ the turnover of the firm; $u_{i t}=$ the error term;

$\left(\frac{I}{K}\right)_{t}=$ Ratio of investment to the capital stock $K=$ rate of accumulation of $K ;\left(\frac{Y}{K}\right)_{t}=$ Ratio of output to the capital stock $K ;\left(\frac{\Pi}{K}\right)_{t}=$ Ratio of profit to the capital stock; $\Delta\left(\frac{I}{K}\right)_{i t-1}^{2}=$ change in the ratio of investment to the stock of capital lagged 2 periods; $\left(\frac{B}{K}\right)_{i t-1}^{2}=$ change in the ratio of the debt to the capital stock lagged 2 periods.

By generating the model with the synthesis of the available data of different Sub-Saharan countries, the interpretation of the estimated results takes account of two approaches: before the decomposition of the samples, and with the taking account of the dimension (size), and the participative relations of financial institutions.

\section{Empirical Results and Interpretations}

They concern two aspects:

\subsection{Interpretation of the Estimation of the Model before the Decomposition of the Sample}

Table 1 presents the results derived from the estimation of model (7) before the decomposition of the sample (the Hausman test). According to the results of the Hausman test, the determined $\chi^{2}$ is equal to 11.9287 . This value is lower than the theoretical $\chi^{2}$ (read) at the $5 \%$ significance level and 7 degrees of freedom (that is to say, 16.088). The Hausman test does not show the existence of a correlation between the individual effect and the explanatory variables. For this reason, this may be a model with purely random effects.

Moreover, we note that the first two exogenous variables $\left(\Delta\left(\frac{I}{K}\right)_{i t-1}\right.$ and $\left.\Delta\left(\frac{I}{K}\right)_{i t-1}^{2}\right)$ have significant coefficients, but their signs are opposite. The sign of the coefficient of the first variable is negative, while that of the second variable is positive. We note that the investment rate of the previous period negatively affects the present rate at an increasing rate.

In effect, the insignificance of the coefficients of variable $\Delta\left(\frac{\Pi}{K}\right)_{i t-1}$ clearly illustrates the fact that the profitability variable is not important enough. Similarly, the estimation result indicates that the capital accumula-

Table 1. Results derived from Equation (7) estimation.

\begin{tabular}{cccc}
\hline Variables & coefficient & t-statistic & probability \\
\hline$\Delta\left(\frac{I}{K}\right)_{i t-1}$ & -3.554 & $(-7.223)$ & $0.0000^{* * *}$ \\
$\Delta\left(\frac{I}{K}\right)_{i t-1}^{2}$ & 0.345 & $(7.765)$ & $0.0000^{* * *}$ \\
$\Delta\left(\frac{\Pi}{K}\right)_{i t-1}$ & 0.418 & $(0.660)$ & 0.2891 \\
$\Delta\left(\frac{Y}{K}\right)_{i t-1}$ & 0.487 & $(3.867)$ & $0.0121^{* *}$ \\
$\Delta\left(\frac{B}{K}\right)_{i t-1}$ & 0.092 & $(4.451)$ & $0.0008^{* * *}$ \\
$\Delta\left(\frac{B}{K}\right)_{i t-1}^{2}$ & -0.842 & $(-2.334)$ & $0.0044^{* *}$ \\
\hline
\end{tabular}

${ }^{* * *}$ Significant at $5 \%,{ }^{* *}$ Significant at $1 \%$. 
tion behaviour of the activity of the previous year, which is taken into account by the ratio of the turnover to the capital stock $\left(\frac{I}{K}\right)_{i t-1}$, has an impact on the rate of investment. This result helps us to distinguish as Daoud and Kammoun [12], the pertinence of the accelerator theory under the imperfections of the capital market assumption. For that reason the accelerator effect, which is taken into account by the explanatory role of demand measured by the turnover, is important.

If we get interested in variables which measure financial constraints, the variable $\Delta\left(\frac{B}{K}\right)_{i t-1}$ has a significant coefficient, but it has a negative sign. This demonstrates the effectiveness of setting a ceiling on indebtedness by financial institutions. The increase in the ratio of the debt to the capital stock reduces the advantage of financing through the debt because of the premium to be paid; in addition to the interest rate without risk (an effect which is due to the agency cost which is captured by the ratio $\Delta\left(\frac{B}{K}\right)_{i t-1}^{2}$ and which therefore re duces the firms' investment expenditures.

The coefficient estimate of $\Delta\left(\frac{B}{K}\right)_{i t-1}^{2}$ is positively significant. It also shows the effectiveness of the existence of costs linked to information asymmetries between the firm and the financial institution of credit. On that account, the higher $(B)$ is, the more incentive problems are severe. These results corroborate with the works of Jaramillo et al. [29] and Daoud and Kammoun [12].

Therefore, it appears that Sub-Saharan firms are experiencing an environment with quite a strong information asymmetry between the borrowers and lenders. In addition, these firms are constrained in their access to external indebtedness owing to the levelling-off of indebtedness.

\subsection{Estimation with Integration of the Dimension and the Participative Relations of Financial Institutions}

In order to integrate the heterogeneity of the firms in the analysis of the impact of financial constraints on the investment decisions of manufacturing firms, we have carried out a categorisation of the firms according to two criteria: the dimension and the participative relationship of financial institutions.

The financial literature states the fact that small firms are put at a disadvantage by the banks, either by higher guarantees, or by high borrowing costs.

Ydriss Ziane [33], Guariglia [34], Hovakimian [35,36] Hsiao and Tahmiscioglu [36] and Daoud and Kammoun [12] underline the fact that a participative relation of financial institutions is profitable to the firm, thanks to better terms and conditions of financing. According to these authors, the closeness of the relations between financial institutions and firms has the effect of reducing interest costs and of being less financially constrained.

The dimension of the firm is considered as a factor of differentiation of the impact of financial constraints on the rate of investment. Several criteria are used to appreciate the firm's dimension, namely the number of employees in the firm, the turnover achieved, and total assets.

In the present study, we consider a large firm as any structure making a turnover of higher than 2 billions CFA Francs, and a small firm as a firm whose turnover is lower that this value.

On the basis of this criterion (the participative relations of financial institutions), we have distinguished the firms where financial institutions appear in their property structure, and those where financial institutions do not have participative relations. In order for financial variables to be different according to their dimension (a participative relation of financial institutions), we have defined a dimension control variable (DIME) which is equal to 1 if the firm is large (there exists a relation between firm and financial institution) and zero if not.

For that reason, to estimate the coefficient of $\Delta\left(\frac{B}{K}\right)_{i t-1}^{2}$ for large firms we estimate the coefficient of the variable $\left(\Delta\left(\frac{B}{K}\right)_{i t-1}^{2} \times\right.$ DIME). This has helped us estimate the following equations respectively:

Equation 1

$$
\begin{aligned}
\Delta\left(\frac{I}{K}\right)_{i}= & a_{1} \Delta\left(\frac{I}{K}\right)_{i t-1}+a_{2} \Delta\left(\frac{I}{K}\right)_{i t-1}^{2}+a_{3} \Delta\left(\frac{\Pi}{K}\right)_{i t-1}+a_{4} \Delta\left(\frac{Y}{K}\right)_{i t-1}+a_{5} \Delta\left(\frac{B}{K}\right)_{i t-1}^{2} \times \mathrm{DIME} \\
& +a_{5}^{\prime} \Delta\left(\frac{B}{K}\right)_{i t-1}^{2} \times(1-\mathrm{DIME})+a_{6} \Delta\left(\frac{B}{K}\right)_{i t-1} \times \mathrm{DIME}+a_{6}^{\prime} \Delta\left(\frac{B}{K}\right)_{i t-1} \times(1-\mathrm{DIME})+u_{i t}
\end{aligned}
$$

\section{Equation 2}




$$
\begin{aligned}
\Delta\left(\frac{I}{K}\right)_{i}= & a_{1} \Delta\left(\frac{I}{K}\right)_{i t-1}+a_{2} \Delta\left(\frac{I}{K}\right)_{i t-1}^{2}+a_{3} \Delta\left(\frac{\Pi}{K}\right)_{i t-1}+a_{4} \Delta\left(\frac{Y}{K}\right)_{i t-1}+a_{5} \Delta\left(\frac{B}{K}\right)_{i t-1}^{2} \times \mathrm{RPIF} \\
& +a_{5}^{\prime} \Delta\left(\frac{B}{K}\right)_{i t-1}^{2} \times(1-\mathrm{RPIF})+a_{6} \Delta\left(\frac{B}{K}\right)_{i t-1} \times \mathrm{RPIF}+a_{6}^{\prime} \Delta\left(\frac{B}{K}\right)_{i t-1} \times(1-\mathrm{RPIF})+u_{i t}
\end{aligned}
$$

According to the Hausman test results, the $\chi^{2}$ determined by the first and the second equation is equal to 11.989 and 11.402 respectively. These values are lower than that of the theoretical $\chi^{2}$ which is equal to 17.889 at the $5 \%$ significance level.

From the preceding presentation, we can maintain the lack of correlation between the individual effect and explanatory variables. Both models have purely random effects.

The examination of Table 2 shows that the coefficients of exogenous variables $\Delta\left(\frac{I}{K}\right)_{i t-1}^{2}, \Delta\left(\frac{I}{K}\right)_{i t-1}$, $\Delta\left(\frac{\Pi}{K}\right)_{i t-1}, \Delta\left(\frac{Y}{K}\right)_{i t-1}$ remain unchanged in the results of both estimations, and the interpretation made previously as to their significance remains the same.

As concerns the variable $\Delta\left(\frac{B}{K}\right)_{i t-1}^{2}$, it has a positive and significant effect on the investment expenditures of small firms. On the other hand, for large firms the coefficient of this variable is negative and insignificant. Similarly for the second variable which represents the indebtedness ceiling constraint, $\Delta\left(\frac{B}{K}\right)_{i t-1}$ its coefficient is negative and significant for small firms. Both of these results imply that information problems and the indebtedness ceiling influence the rate of investment.In addition, these results agree with those obtained by Jaramillo

Table 2. Estimation Results of 2 Equations.

\begin{tabular}{ccc}
\hline Coefficients & $\begin{array}{c}\text { Estimation with the } \\
\text { taking account of the } \\
\text { firms' dimensions. }\end{array}$ & $\begin{array}{c}\text { Estimation with the taking account } \\
\text { of the participative relations of } \\
\text { financial institutions }\end{array}$ \\
\hline$a_{1}$ & $-3.556^{* * *}(-7.367)$ & $-3.524^{* * *}(-7.223)$ \\
$a_{2}$ & $0.483^{* * *}(7.777)$ & $0.472^{* * *}(7.765)$ \\
$a_{3}$ & $0.490(0.677)$ & $0.486(0.660)$ \\
$a_{4}$ & $0.499^{* *}(3.658)$ & $0.692^{* * *}(3.867)$ \\
$a_{5}$ & $-0.650(-0.191)$ & $-0.356(-0.108)$ \\
$a_{5}^{\prime}$ & $0.092^{* * *}(4.451)$ & $0.088^{* * *}(4.430)$ \\
$a_{6}$ & $1.490(0.337)$ & $1.573(0.879)$ \\
$a_{6}^{\prime}$ & $-0.842^{* *}(-3.212)$ & $-0.768^{* *}(-2.334)$ \\
\hline
\end{tabular}

Sources: The figures between parentheses represent the values of $t$-student statistics. et al. [29] and Daoud and Kammoun [12] by confirming the results according to which small firms and growth firms are more constrained in their access to external financing, given that they are young and have less time indeed to make themselves known by lenders and to establish relations of trust with the latter. Actually, the estimation which makes a distinction between firms according to their dimensions show that this criterion is relevant

The effect of these two financial constraints on investment according to the criterion of participative relations of financial investment with the firm presents pertinent results. The firms where financial institutions appear in their property structure are more capable of finding external financial resources there. These pertinent results are brought out by the insignificance of indebtedness coefficients $\left(a_{5}\right.$ and $\left.a_{6}\right)$. While these coefficients are significant for the firms with which the financial institutions have no participative relations. These firms are more constrained in obtaining financing on the credit market.

\section{Conclusions}

The purpose of this paper was to explain the influence of financial constraints on the investments of manufacturing firms in the context of Sub-Saharan countries. In this framework, we empirically tested two constraints which may affect the investment decisions of a firm. These constraints correspond to a levelling-off of the indebtedness level and the increase in the cost of the debt according to the amount borrowed reflecting the asymmetry of information which exists between the lender and the borrower. The estimation results of Euler's capital accumulation equation derived by Jaramillo et al. [29] and revisited by Daoud and. Kammoun [12], help us to conclude that the manufacturing firms of Sub-Saharan Africa (belonging to different activity sectors) are witnessing a financial environment made up of a strong information asymmetry between the lenders and the borrowers. The empirical results also add that these firms are subject to constraints in their access to external financing owing to the levelling-off of the debt.

In addition, the effect of information problems and of the levelling-off of indebtedness on the rate of investment according to the dimension criterion, show that small firms are put to a disadvantage by the financial institutions either by high borrowing costs, or by high 
guarantees. Similarly, the distinction of the effect of two financial constraints on investment according to the criterion of a participative relation of financial institutions indicates that the firms where the financial institutions appear in their property structure are more capable of finding external financial resources there, thanks to the relations of trust between financial institutions and the firms. Generally speaking, the firms are less constrained in obtaining financing on the credit market.

\section{REFERENCES}

[1] A. Glesne and G. Legris, "La Décision d'Investissement des Grandes Sociétés Françaises une Approche Econométrique," Revue économique, Vol. 25, No. 1, 1974, pp. 4974.

[2] F. Modigliani and M. Miller, "The Cost of Capital, Corporate Finance, and the Theory of Investment," American Economic Review, Vol. 48, No. 3, 1958, pp. 97-261.

[3] S. M. Fazzari, R. G. Hubbard and B. C. Peterson, "Financing Constraints and Corporate Investment," Brookings Papers on Economic Activity, Vol. 1, No. 1, 1988, pp. 141-195. doi: $10.2307 / 2534426$

[4] R. Carpenter and A. Guariglia, "Cash Flow, Investment, and Investment Opportunities: New Tests Using UK Panel Data," University of Nottingham Discussion Paper n 03/24, 2003.

[5] K. Gugler, D. C. Mueller and B. B. Yurtoglu, "Marginal $q$, Tobin's q, Cash-Flow and Investment," Southern Economic Journal, Vol. 70, No. 3, 2004, pp. 512-531. doi: $10.2307 / 4135328$

[6] A. Minton and C. Schrand, "The Impact of Cash Flow Volatility on Discretionary Investment and the Costs of Debt and Equity Financing," Journal of Financial Economics, Vol. 54, No. 3, 1999, pp. 423-460. doi:10.1016/S0304-405X(99)00042-2

[7] S. C. Vogt, "The Cash Flow/Investment Relationship: Evidence from U.S. Manufacturing g Firms," Financial Management, Vol. 23, No. 2, 1994, pp. 3-20. doi: $10.2307 / 3665735$

[8] S. N. Kaplan and L. Zingales, "Do Financing Constraints Explain Why Investment is Correlated with Cash-Flow?" NBER Working Paper, N5267, 1995.

[9] A. Heitor and M. Campello, "Financial Constraints, Asset Tangibility, and Corporate Investment," Review of Financial Studies, Vol. 20, No. 5, 2007, pp. 1429-1460. doi:10.1093/rfs/hhm019

[10] M. T. Whited, "Debt, Liquidity Constraints, and Corporate Investment: Evidence from Panel Data," Journal of Finance, Vol. 47, No. 4, 1992, pp. 1425-1460. doi:10.1111/j.1540-6261.1992.tb04664.x

[11] S. Bond and C. Meghir, "Dynamic Investment Models and the Firm's Financial Policy," Review of Economic Studies, Vol. 61, No. 2, 1994, pp. 197-222. doi: $10.2307 / 2297978$

[12] Y. Daoud and A. Kammoun, "Contraintes Financières et Comportement d'Investissement: Le cas des Entreprises
Tunisiennes Cotées," Revue Libanaise de Gestion et d'Économie, Vol. 1, No. 5, 2011, pp. 1-33.

[13] S. N. Kaplan and L. Zingales, "Do Investment Cash-Flow Sensitivities Provide Useful Measures of Financing Constraints?" Quarterly Journal of Economics, Vol. 115, No. 2, 1997, pp. 707-712. doi:10.1162/003355300554782

[14] S. Nivoix, J. Faouzzi and W. Saidani, "Sensibilité des Investissements aux Cash-Flows et Degré de Contrainte Financière des Firmes: Le cas des keiretsujaponais," Working Paper, Université de Tunis, 2003.

[15] T. Tobin, "A General Equilibrium Approach to Monetary Theory," Journal of Money, Vol. 1, No. 1, 1969, pp. 1529. doi: $10.2307 / 1991374$

[16] E. Malinvaud, "Profitability and Unemployment," Cambridge University Press, Cambridge, 1980.

[17] E. Malinvaud, "The Challenge of Macroeconomic Understanding," BancoNazionale Del Lavoro Quarterly Review, Vol. 1, No. 162, 1987, pp. 219-238.

[18] F. Modigliani and M. Miller, "Some Estimates of the Cost of the Capital to the Electric Utility Industry, 19541957," American Economic Review, Vol. 56, 1957, pp. 333-391.

[19] F. Hayashi, "Tobin's Marginal q and Average q: a Neoclassical Interpretation," Econometrica, Vol. 50, No. 1, 1982, pp. 213-224. doi:10.2307/1912538

[20] E. Malinvaud, "Econometric Methodology at the Cowles Commission: Rise and Maturity," Econometric Theory, Vol. 4, No. 2, 1988, pp. 187-209. doi:10.1017/S0266466600012020

[21] M. Jensen, "Agency Cost of Free Cash-Flow, Corporate Finance, and Takeovers," American Economic Review, Vol. 76, No. 2, 1986, pp. 323-329.

[22] M. Jensen and W. Meckling, "Theory of the Firm: Managerial Behavior, Agency Costs, and Ownership Structure," Journal of Financial Economics, Vol. 3, No. 4, 1976, pp. 305-360. doi:10.1016/0304-405X(76)90026-X

[23] L. Lang and R. Litzenberger, "Dividend Announcements: Cash Flow Signalling vs. Free Cash Flow Hypothesis," Journal of Financial Economics, Vol. 24, No. 1, 1989, pp. 181-191. doi:10.1016/0304-405X(89)90077-9

[24] A. Heitor and M. Campello, "Financial Constraints and Investment-Cash Flow Sensitivities: New Research Directions," Working Paper at the Utah Winter Finance Conference, 2001.

[25] M. Jaffee and F. Modigliani, "A Theory and Test of Credit Rationing," The American Economic Review, Vol. 59, No. 7, 1969, pp. 850-872.

[26] A. B. Abel, "Investment and the Value of Capital," Garland, New-York, 1980.

[27] A. B. Abel and O. Blanchard, "The Present of Profit and Cyclical Movements in Investment," Econometrica, Vol. 54, No. 2, 1986, pp. 249-273. doi:10.2307/1913150

[28] V. P. Azofra and F. J. Lopez, "Déterminants Financiers de 1'Investissement en Capital Fixe: Le cas Espagnol," Revue Économie Industrielle, Vol. 86, No. 86, 1998, pp, $25-48$.

[29] F. Jaramillo, F. Schiantarelli and A. Weiss, "Capital 
Market Imperfection before and after Financial Liberalisation: An Euler Equation Approach to Panel Data for Ecuadorian Firm," Journal of Development Economics, Vol. 51, No. 2, 1996, pp. 367-386. doi:10.1016/S0304-3878(96)00420-8

[30] F. Rosenwald, "L'Impact des Conditions Financières sur la Décision d'Investissement," Économie et Prévisions, No. 1-2, 2001, pp. 341-342,

[31] M. Arellano and S. Bond, "Some Tests of Specification for Panel Data: Monte Carlo Evidence and an Application to Employment Equations," The Review of Economic Studies, Vol. 58, No. 2, 1991, pp. 277-297. doi: $10.2307 / 2297968$

[32] J. A. Hausman, "Specification Tests in Econometrics," Econometrica, Vol. 46, No. 6, 1980, pp. 1251-1271. doi: $10.2307 / 1913827$

[33] Y. Ziane, "Nombre de Banques et Relation de Crédit, une Étude Empirique," Revue Économique, Vol. 55, No. 3, 2004, pp. 415-428.

[34] A. Guariglia, "Internal Financial Constraints, External Constraints, and Investment Choice: Evidence from a Panel of UK Firms," Journal of Management Finance, Vol. 32, No. 9, 2008, pp. 1795-1809.

[35] G. Hovakimian, "Determinants of Investment Cash-Flow Sensitivity," Financial Mangement, Vol. 38, No. 6, 2009, pp. 161-183. doi:10.2307/1913827

[36] C. Hsiao and A. K. Tahmiscioglu, "A panel Analysis of Liquidity Constraints and Firm Investment," Journal of the American Statistical Association, Vol. 92, 1997, pp. 455-465. 